IRA-International Journal of Technology \& Engineering

ISSN 2455-4480; Vol.04, Issue 02 (2016)

Pg. no. 117-125

Institute of Research Advances

http://research-advances.org/index.php/IRAJTE

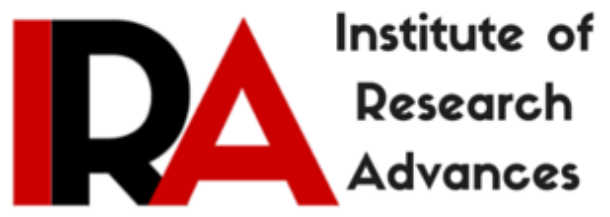

\title{
Health Information Systems: The Issues related to Governmental Initiatives, Political and Economics-A Theoretical Overview
}

\author{
P. K. Paul ${ }^{1}$, A. Bhuimali ${ }^{2}$ M. Ghose ${ }^{3}$ \& Poovammal. E. ${ }^{4}$ \\ IFBAS, Indian Institute of Engineering Science and Technology (IIEST), \\ Shibpur- An Institute of National Importance, Howrah, West Bengal, India. \\ ${ }^{2}$ Vice Chancellor, Raiganj University, Raiganj, West Bengal, India. \\ ${ }^{3}$ Dean (Academics), Sikkim Manipal University, Gangtok, Sikkim, India. \\ ${ }^{4}$ HOD, Computer Engineering Department, SRM University, Kattankulathar, Tamilnadu, \\ India.
}

Type of Review : Peer Reviewed.

DOI: http://dx.doi.org/10.21013/jte.v4.n2.p3

\section{How to cite this paper:}

Paul, P., Bhuimali, A., Ghose, M., \& E., P. (2016). Health Information Systems: The Issues related to Governmental Initiatives, Political and Economics-A Theoretical Overview. IRAInternational Journal of Technology \& Engineering (ISSN 2455-4480), 4(2), 117-125. doi:http://dx.doi.org/10.21013/jte.v4.n2.p3

(C) Institute of Research Advances

\section{(c) B B-NC}

This work is licensed under a Creative Commons Attribution-Non Commercial 4.0 International License subject to proper citation to the publication source of the work.

Disclaimer: The scholarly papers as reviewed and published by the Institute of Research Advances (IRA) are the views and opinions of their respective authors and are not the views or opinions of the IRA. The IRA disclaims of any harm or loss caused due to the published content to any party. 


\section{ABSTRACT}

Health Information System or Medical Information Systems is an important and valuable concept which is mainly dedicated to the Health related issues and solutions. The Health Information System is combines with the management and also economical aspects for its real and healthy solutions. The Health Information System is the important name in most of the developed countries for their healthy and sophisticated healthcare systems. The Health Information System thus needs to be a valuable agenda in medical and clinical systems. The Health Information System is only possible with the initiation of the solid Health Informatics practice. The domain and knowledge field of Health Information System is deals with the fundamentals of Information Studies, Computing \& Information Technologies, Management Sciences with the Bio Sciences such as Physiology, Life Science, Clinical and Health Management, Human Body etc. The Health Information System has many problems in the spectrum of technologies as well as in the field of economies etc. This is a kind of conceptual paper and mainly illustrated the issues of Governance, Policies, Economics etc for solid and healthy Health Information System building.

\section{Keywords-}

Health Information System, Health Informatics, Public Health, Health Management, Bio Information Sciences, Health Related Issues, Developing Countries \& Issues, Health Engineering

\section{Introduction-}

Health Information System is a techno-health-social knowledge cluster responsible for the designing and development of health and medical systems of the health institutions. And the health institutes are include the Hospitals, Nursing Home, Clinics, Diagnostics Centre, Health Counseling Centers etc. Importantly the Health Information System is also responsible for the overall healthy health information systems creation and management [01], [03], [21]. The Health Information System is needed for solid public health systems creations. The issues of this area in the initial time were mainly related with the technologies and management. But there are many other areas which not at all touches in the academic and research wings. This paper tries to discuss these critical issues and agendas with solid socio-technical review point of view [05], [09], [23]. The Health Information System is needed for the robust information systems and infrastructure development related to the health and medical world including the Pharma and clinical research world. Importantly the Health Information System is a management focused field. The Health Information System is also treated as Medical Information Systems; though the periphery and scope wise it is large (See Fig: 1 for more clarification). Importantly the issues related to Health Information Systems are valuable as the critical analysis, SWOT of Health Information System ultimately requires for solid and healthy Health and Medical Informatics practice. The Social Health and Health Systems integration brings the Public Health Systems and the Health Information System is purely dedicated to achieve this condition as much as possible [02], [04], [22].

\section{Objectives \& Agendas-}

The core aim and objective of this conceptual paper is to discus about various aspects of the Health Information System and few of them are depicted as under-

- To know basic about the Health Information System including the fundamental meanings, characteristics etc.

- To learn about the conceptual overview of the Health Information System in the perspectives of SWOT analysis.

- To learn the Health Information System in Socio-Technical-Health point of views in easy and contemporary context. 
- To know about the Health Information System's perspectives related to the philosophy, sociology, management and economics.

- To dig out the important and valuable concept related to the Health Information System implementation in Public Health Engineering context.

- To learn the strategies, remedies of the solid and healthy Health Information System design, development, evaluation and recycling etc.

\section{Health Information Systems: The Background-}

- Health Information System is governed by the procedure and which include but not limited to healthy and smart technologies, techniques and several computing systems. Solid and brilliant Health Information System and managerial tools and technologies play a great role for healthy HIS creation [06], [07], [24]. Healthcare systems is fall under the service sector domain and importantly comprises with the information and content such as large number of texts, coded content, image and others in the field of health and medical sciences. The contents are includes the patient's brief details, brief information and so on. In the health administration and management, the Health Information System played an important role [11], [15], [26]. The tools and technologies have changing day by day (the latest of managerial and technological skills in this regard listed in the Fig: 2). It is important to note that data may be stored in digital format and it will no doubt bring and improve the healthy medical systems in many contexts. The fully integrated Health Systems is positively possible with the Health Information System. Infrastructure

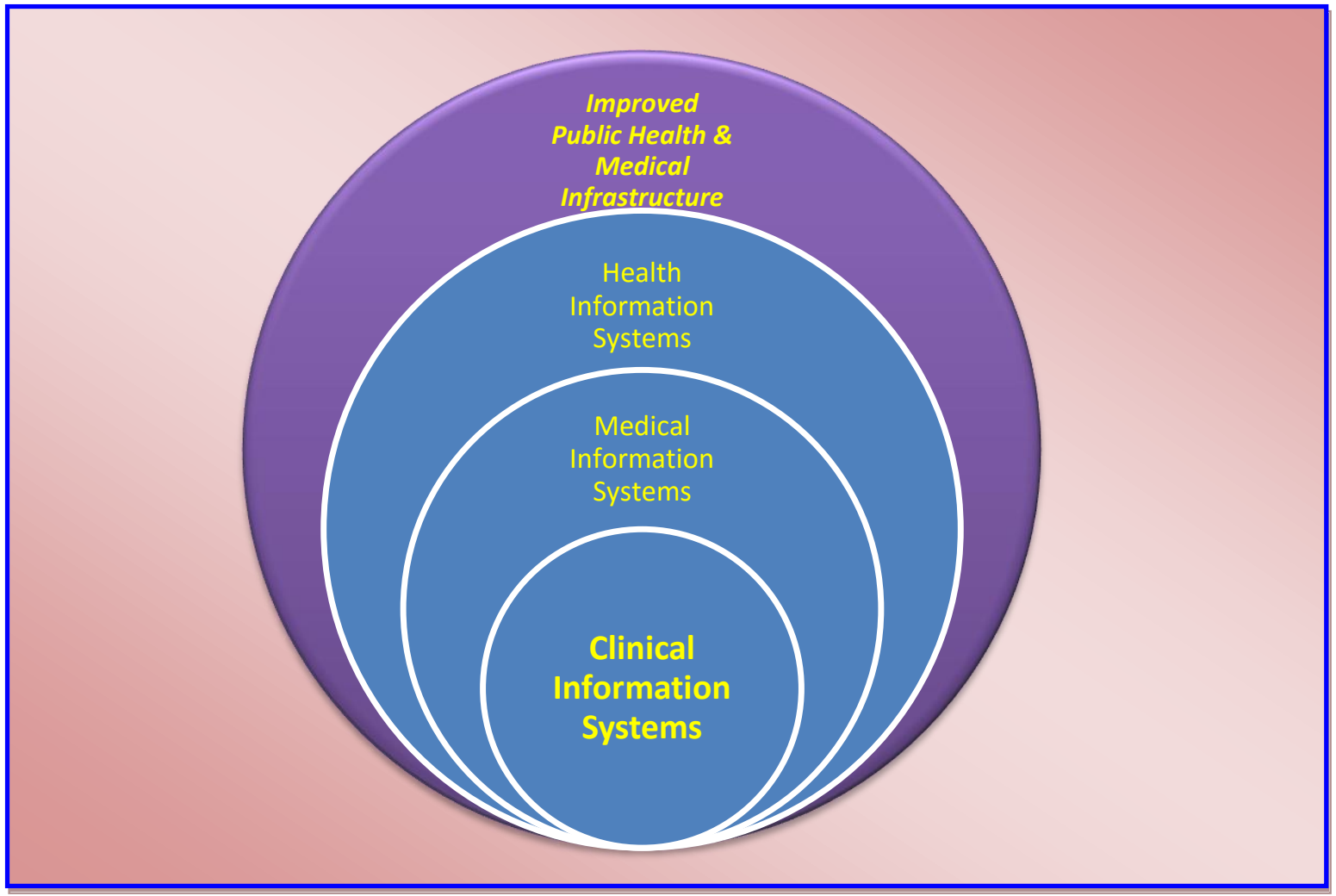

Fig: 1 Depicted the Health Information Systems and Related areas and their ultimate aim and agenda 
The Health Information System has many kind of challenges and issues. There are various types of aspects deals with the Health Information System such as symptom and incidence of diseases, health illness and quality of life. Moreover the functional and emotional kinds of health status are also valuable issues [12], [30]. Understanding including the identification of the Health Information System is a critical issue and thus its solution also an important matter. Better solutions, better planning, protocol, effective management are most valuable issues of the Health Information System. Health and medical systems need to take care about the economic, political, philosophical aspects. The other issues are include as follows.

\section{Governmental Issues Vis-à-Vis HIS: International Contexts-}

In the Australia the specific and dedicated mission is dedicated to inform community discussion as well as supports public policy making of medical, health issues and there should be best alternative of coordinating, developing, analyzing as well as modernizing information systems in health contexts [13], [30]. Ultimately these improve the health and welfare services and solid research and development in medical domain. The Australian Institute of Health and Welfare has taken several initiatives for the improvement of the healthcare systems. The National Health Information agreement completed between the state, common wealth including the territory health organizations and foundations [14], [29]. And all these cases the $\mathrm{AIH} \& \mathrm{~W}$ play an important noticeable role.

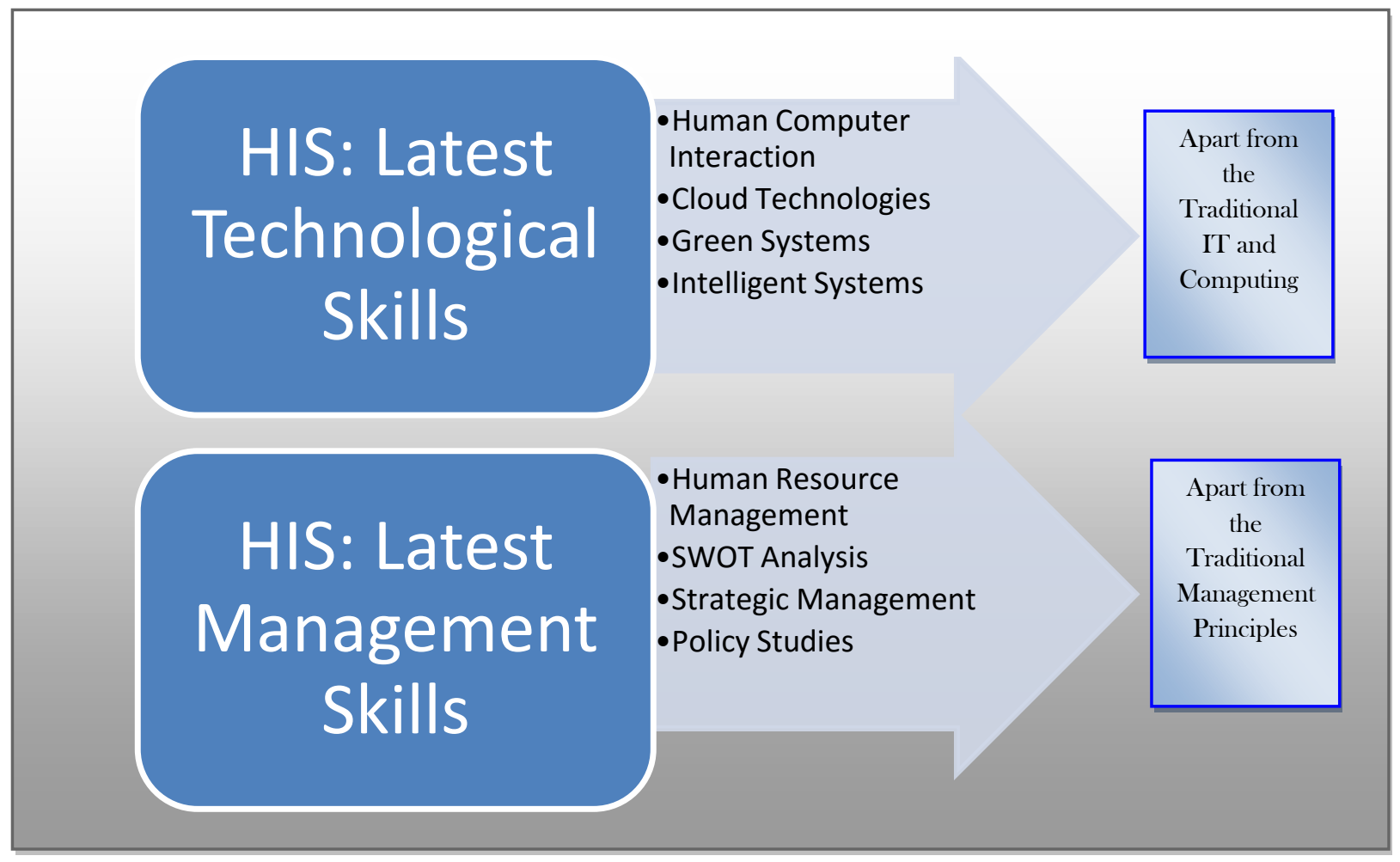

Fig: 2-Showing the latest technologies and emerging management skill sets requirements in the context of Health Information Systems

Among the important initiatives some important and valuable are include the medical services, mental health, public healthcare, community health and other matters. The important issues are HR medical issues, statistical issues, health population surveys, records related to the population, surveillance, governmental information policy (state and national) [10], [16], [25]. 
As far as United States in concerned the similar agencies and agenda established by the Agency for better and important healthcare policy and research (AHCPR) consist with several components. The Computer Based Patient Record Institute (CPRI) was also established in the 1991. It is important to note that more importance was carried later on for healthy and improved patient record and information systems creation [17], [26]. For better and healthy Health Information System all the perspective of philosophical, political, economical aspects are important and these depicted in the next sections [18], [27].

\section{Economical \& Political Aspects of HIS-}

The Health Information System also promotes and develops the economical status as well as situations. In 1992 the Organization for Economic Co-Operation and Development expressed that the growth of the health and allied expenditure and has exceeded and also helps in the GDP. Importantly this is resulted the promotion of in-general healthcare systems. It is important to note that the maximize the reimbursement of the health and complete health and clinical systems with the proper medical governance [19], [20], [28].

The economical and financial matters lead the awareness of health among the common people and it is finally lead many achievements which includes cardiovascular disease, cancer and some other type of injuries. The Medical Treatment Effectiveness Program is also important and responsible for bringing smarter Health Information Systems. The safety, efficiency and effectiveness many ways possible with technology enable Health Information Systems. Importantly the MEDTEP is dedicated for better and quality services, review criteria and improved feedback systems [29], [31], [34]. In the USA in 1983 they utilized the healthcare expenditure. The details of activities are as follows-

- The Classification of the Patients.

- Diagnostics Related Groups.

The Australia is also played important steps for building and development of the Healthcare and Medical Information System in the Country. In the 1988 the second round of Medicare Agreement negotiated within the commonwealth, state and territory health authorities. Though after five year, another third Medical agreement was introduced.

Similarly United Kingdom is another nation who already taken initiatives for better and healthy medical informatics practice. The main agenda was improving the Health Information System for better clinical practices and public health development. The National Health Service played a lead role for the solid practice of Health IT and several issues such as ICD9, ICDP-CM enhance the overall health systems of the UK [32], [35].

\section{Philosophical Aspects and HIS-}

The matter of health and medical systems play a lead role for the development of solid health information systems designing, development and modernization and all these cases the philosophical views play a great role. There is a significant change in the field of social structure, occupational structure and also the environmental issues.

Importantly medical interventions have also designed to respond to the physical fact of the poor medical systems and to a lesser context to the psychological matters.

Practically the population health is not a discreet domain of the medical practice. Virtually the improved Health Information System depends on the bellow mentioned matters-

- Defining problems.

- Understanding and accepting the problems. 
- Identification and similar steps in better interventions.

- Preventative Systems.

According to the experts the political interface including the financial aspects lead the governmental authorities for the improved philosophy of the primary to secondary health systems. The health related philosophical aspects have been implement and installed in some of the conferences held in many countries and that play a wonderful role for improved Health Information Systems [30], [33]. So it is important that the philosophical, economical and social aspects play a lead role for Health Information System apart from the following conventional technologies -

- Database Technologies.

- Networking Technologies.

- Communication Technologies.

- Multimedia Technologies.

- Computing Technologies.

The emerging technologies such as the Cloud Computing, Green Information Systems, Human Computer Systems also play a lead for solid development of Information Infrastructure development in the context of health and medical systems. .

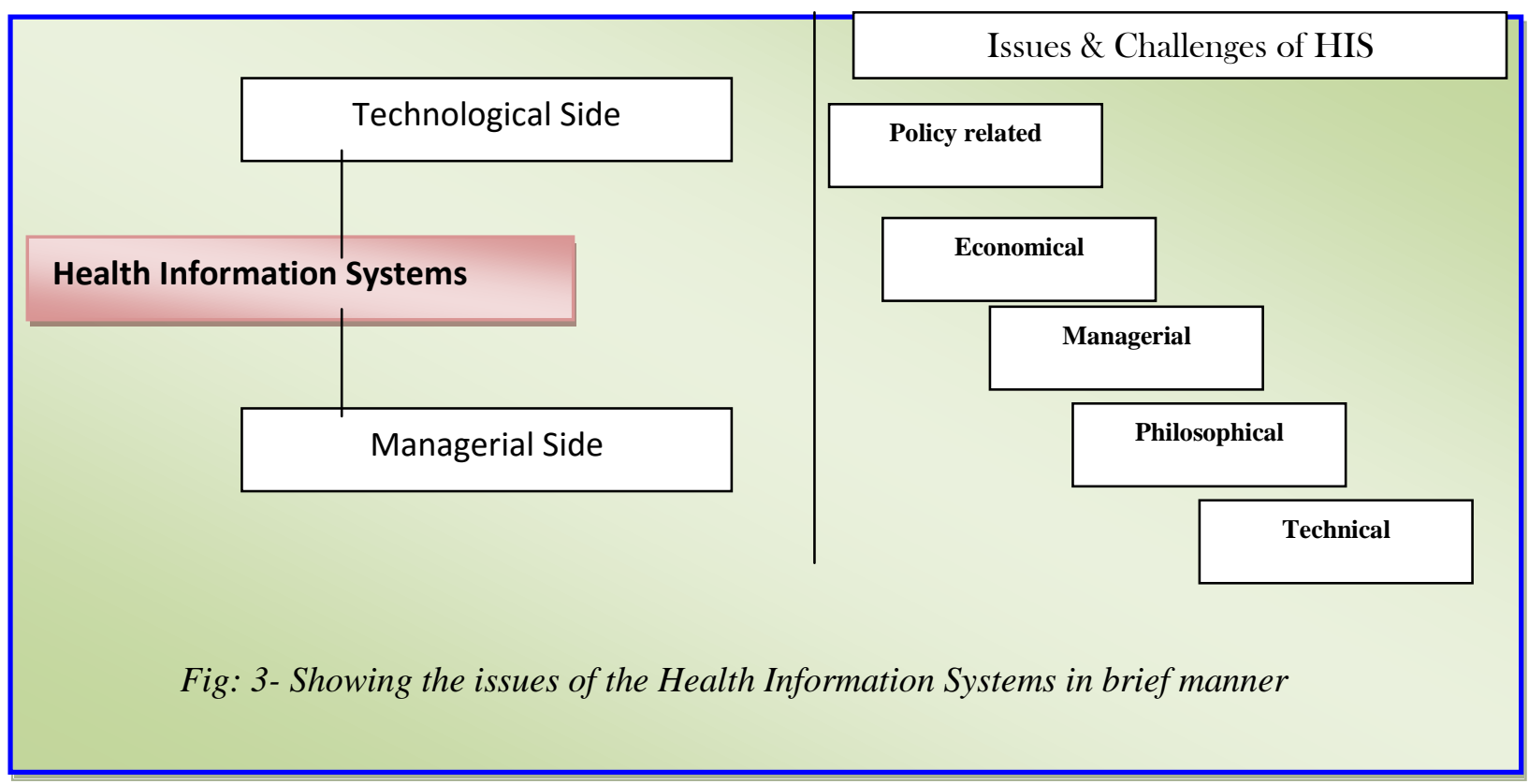

\section{Findings-}

- The Health Information System is an interdisciplinary knowledge domain interconnected with the computing, informatics, information systems, sociology, health sciences, management sciences etc.

- The Health Information System is needs proper and healthy solutions in the area of sociology, philosophy etc

- Health Information System is a kind of domain and practicing field both. The domain Health Information System needs critical analysis etc. 
- The solid and healthy success of the Health Information System is only possible only when healthy and sophisticated economical and financial measures will be taken.

- The Health Information System is very much important and valuable for betterment in the hospitals, diagnostics centre, telemedicine systems etc.

- The aspects related to the philosophy, economics and sociology in the context of Health Information System is very much important and urgent but the research activities in these areas are very much limited.

\section{Suggestions and Recommendation-}

- Solid and sophisticated Health Information System is only possible when important and valuable steps will be taken by the respective states and union territories and country as a whole. Thus proper steps from governmental level are very much important and crucial.

- Similarly the real and healthy Health Information System possible by offering the proper educational opportunities in the field in the universities, engineering colleges and other Higher Educational Institutes etc.

- The Health Information System may be offered by the Public Health department along with the initiatives from the NGO, Social Welfare Department etc.

- Proper Funding and healthy financial support are very much important and needed for the solid and real-time Health Information System creation.

- Apart from the design, development of the Health Information System; a healthy one may also created by the evaluation systems etc.

\section{Conclusion-}

Health Information System is important name for the real and healthy medial information infrastructure creation powered by the technologies and systems. The Health Information System needs proper initiatives and steps for solid implementation of the medical information management. Governmental initiatives including better policies are urgent for better Health and Medical Informatics practice and ultimately for the sophisticated Public Information Systems development. The Health Information System is mainly supported by the technologies such as Computing and Information. Thus apart from economical, social, managerial issues it is important and urgent that the Health Information System should concentrated on the latest technologies of the software, hardware, networking and database systems.

\section{References-}

[1] Cohen, Eli B. and Nycz Malgorzata Learning Objects and E-Learning: an Informing Science Perspective. Interdisciplinary Journal of Knowledge and Learning Objects, 2006; 2(02): 20-23

[2] Ahmadi, H., Nilashi, M., \& Ibrahim, O. (2015). Organizational decision to adopt hospital information system: An empirical investigation in the case of Malaysian public hospitals. International journal of medical informatics, 84(3), 166-188.

[3] Bertelsen, L. B. P., \& Christian, N. Ø. H. R. (2015). Challenges in Improving Health Care by Use of Health Informatics Technology. Techno-Anthropology in Health Informatics: Methodologies for Improving Human-Technology Relations, 215, 3.

[4] Cummings, E., Borycki, E. M., \& Madsen, I. (2015). Teaching nursing informatics in Australia, Canada and Denmark. Context Sensitive Health Informatics: Many Places, Many Users, Many Contexts, Many Uses, 218, 39. 
[5] DeSouza, S. I., Rashmi, M. R., Vasanthi, A. P., Joseph, S. M., \& Rodrigues, R. (2014). Mobile phones: the next step towards healthcare delivery in rural India?. PloS one, 9(8), e104895.

[6] Friedman, C. P. (2013). What informatics is and isn't. Journal of the American Medical Informatics Association, 20(2), 224-226.

[7] Fridsma, D. B. (2016). The scope of health informatics and the Advanced Health Informatics Certification. Journal of the American Medical Informatics Association, 23(4), 855-856.

[8] Gadd, C. S., Williamson, J. J., Steen, E. B., Andriole, K. P., Delaney, C., Gumpper, K., ... \& Turner, P. (2016). Eligibility requirements for advanced health informatics certification. Journal of the American Medical Informatics Association, 23(4), 851-854.

[9] Gadd, C. S., Williamson, J. J., Steen, E. B., \& Fridsma, D. B. (2016). Creating advanced health informatics certification. Journal of the American Medical Informatics Association, 23(4), 848-850.

[10] Gunson, J., \& Chawngthu, L. (2012). Health Economics and Informatics The Gap-Fit of Current Healthcare and Parse Practice. Nursing science quarterly,25(2), 176-181.

[11] Herland, M., Khoshgoftaar, T. M., \& Wald, R. (2014). A review of data mining using big data in health informatics. Journal of Big Data, 1(1), 1.

[12] Hunter, K., McGonigle, D., \& Hebda, T. (2013). The integration of informatics content in baccalaureate and graduate nursing education: a status report.Nurse educator, 38(3), 110-113.

[13] Jiang, Q., Ma, J., Ma, Z., \& Li, G. (2013). A privacy enhanced authentication scheme for telecare medical information systems. Journal of medical systems, 37(1), 1-8.

[14] Joshi, A., \& Perin, D. M. (2012). Gaps in the existing public health informatics training programs: a challenge to the development of a skilled global workforce. Gaps in the Existing Public Health Informatics Training Programs: A Challenge to the Development of a Skilled Global Workforce/AHIMA, American Health Information Management Association.

[15] Khalifa, M. (2013). Barriers to health information systems and electronic medical records implementation. A field study of Saudi Arabian hospitals.Procedia Computer Science, 21, 335-342.

[16] Kumari, S., Khan, M. K., \& Kumar, R. (2013). Cryptanalysis and improvement of 'a privacy enhanced scheme for telecare medical information systems'. Journal of medical systems, 37(4), 1-11.

[17] Low, C., \& Chen, Y. H. (2012). Criteria for the evaluation of a cloud-based hospital information system outsourcing provider. Journal of medical systems,36(6), 3543-3553.

[18] Luna, D., Almerares, A., Mayan, J. C., Gonzalez Bernaldo de Quiros, F., \& Otero, C. (2014). Health informatics in developing countries: going beyond pilot practices to sustainable implementations: a review of the current challenges. Healthcare informatics research, 20(1), 3-10.

[19] Nabovati, E., Vakili-Arki, H., Eslami, S., \& Khajouei, R. (2014). Usability evaluation of Laboratory and Radiology Information Systems integrated into a hospital information system. Journal of medical systems, 38(4), 1-7.

[20] Paton, C., Househ, M., \& Malik, M. (2013). The challenges of publishing on health informatics in developing countries. Applied clinical informatics, 4(3), 428-433.

[21] Paul, P.K., (2012) "Medical 2.0: The tool for proper Information Transfer Cycle (ITC) among the Medical Professionals and Physician with special reference to its difference with Health 2.0" in International Journal of FEE, 4 (2), 183-190

[22] Paul, P.K., A. Kumar, D. Chaterjee (2012) "Health Informatics and its Practice: Emerging Domain of Information Science-Indian Scenario" in Current Trends in Biotechnology and Chemical Research, 2 (2) 83-87

[23] Paul, P.K., D Chatterjee, M Ghosh (2012) "Medical Information Science: Emerging Domain of Information Science and Technology (IST) for sophisticated Health \& Medical Infrastructure Building - An Overview” in International Scientific Journal of Sports Science, 1 (2) -97-104 
[24] Paul, P.K., D Chatterjee, M Ghosh (2012) "Neural Networks: Emphasizing its Application in the World of Health and Medical Sciences" in Journal of Advances in Medicine, 1 (2), , -17-23

[25] Paul, P.K., M Ghosh (2013) "Web 2.0 and its Possible, Emerging and Future Domain Related to Health and Medical Sciences" in Journal of Information Technology and Engineering, 4 (2), 51-55

[26] Paul, P.K., M Ghosh (2013) "Cloud Computing and its possible utilization in Health and Hospital Administration" in Journal of Business Management [JBM]- An International Journal, 5 (2), 147152

[27] Paul, P.K., Jhuma Ganguly (2013) "Medical and Health 2.0: Important and possible Interdisciplinary Domain of Information Science-Overview with possibilities, Challenges and Issues" In Scholars Journal of Applied Medical Sciences (SJAMS), 1 (6), 1066-1069

[28] Paul, P.K., (2013) "Medical 2.0 and Health 2.0: Contemporary Information and Communication Tool-A Conceptual Study” in Journal of Advances in Medicine, 2 (2), 67-74

[29] Paul, P.K., R.K. Sinha, J. Ganguly, M. Ghosh (2013) "HCI, Usability Engineering and Cloud Computing in Healthcare and Medical Domain: A Possible Overview" in Current Trends in Biotechnology and Chemical Research (An International Journal 4(1), -73-77

[30] Paul, P.K., J. Ganguly, A. Sinha (2013) "Cloud Based Medical and Health Systems: Current Potentiality and Future Opportunities" in National Conference on Emerging Technology Trends in E-Commerce, 9-10 may, 2014, AISECT University, Bhopal Published in Emerging Trends in ECommerce (ISBN-978-81-904719-5-4), by Bundeli Lok Sahitya Sansthan,Madhya Pradesh, India, 43-50

[31] Paul, P.K., M.Ghosh, D.K. Bhattacharyya, J Ganguly (2013) "Information Science and its foci's emphasizing health and medical focuses with Health Information Science and its possibilities in India: Conceptual Study” in The Sci-Tech, Journal of Science \& Technology, 3 (2), 32-39

[32] Paul, P.K., R K Sinha, J Ganguly, M Ghosh (2015) "Health and Medical Information Science and its potentiality in Indian Education Sector" in Journal of Advances in Medicine, 4 (1/2), 31-37.

[33] Qi, X., Wang, Y., Xia, L., Meng, Y., Li, Y., Yu, S., ... \& Zhuang, D. (2015). Cross-sectional survey on public health informatics workforce in China: issues, developments and the future. Public health, 129(11), 1459-1464.

[34] Rigby, M., Ammenwerth, E., Beuscart-Zephir, M., Brender, J., Hyppönen, H., Melia, S., ... \& de Keizer, N. (2013). Evidence Based Health Informatics: 10 years of efforts to promote the principle. Yearb Med Inform, 8(1), 34-46.

[35] Sahu, M., Grover, A., \& Joshi, A. (2014). Role of mobile phone technology in health education in Asian and African countries: a systematic review.International journal of electronic healthcare, 7(4), 269-286.

[36] Yucel, G., Cebi, S., Hoege, B., \& Ozok, A. F. (2012). A fuzzy risk assessment model for hospital information system implementation. Expert Systems with Applications, 39(1), 1211-1218. 